\title{
Criterios \\ San Telmo, siglo XX: el palacio como Seminario Metropolitano
}

Eduardo Mosquera Adell

Catedrático de Historia de la Arquitectura. Universidad de Sevilla

\section{Resumen}

Los distintos usos y renovadas propuestas que vive el Palacio de San Telmo a lo largo del siglo $\mathrm{XX}$, vinculadas en gran medida a las necesidades eclesiásticas del nuevo Seminario, centran el desarrollo del presente artículo, que aporta interesantes conclusiones acerca de los valores patrimoniales, históricos y sobre todo actuales, del edificio y su entorno.
Con el inicio de la vigésima centuria, la identificación del palacio de San Telmo se asocia con la del Seminario Metropolitano de San Isidoro y San Francisco Javier. Se trata del uso predominante dentro de la vida del edificio en su principal discurrir a lo largo del siglo XX, si bien se complementó con otros usos directamente derivados de su posesión por la Iglesia Católica, circunstancia sobrevenida a raíz del legado de la infanta María Luisa Fernanda de Borbón, duquesa de Montpensier.

El palacio se convierte en Seminario en 1901, bajo el pontificado de Marcelo Spínola, abandonándose el viejo colegio de Maese Rodrigo, situado más cerca de la catedral metropolitana, intramuros de la antigua Puerta de Jerez, donde funcionaba desde 1848.

Pronto adquiere el inmueble una nueva dinámica interna, claramente diferenciable de las vividas en etapas anteriores. Se entra en una fase donde con frecuencia se prodigan actuaciones basadas incluso en actitudes autónomas, cuando no ajenas o extrañas respecto de las propias características del edificio preexistente. Las intervenciones contemporáneas suelen derivarse de una nueva lógica de ocupación, históricamente carente de una capacidad de relación que pudiera estar encaminada a potenciar al inmueble como un hecho cultural de particular interés.

Puede decirse que una perspectiva patrimonial sobre el mismo tardará en producirse. Y que ésta sólo se ha desarrollado parcialmente. Hasta la fecha, el inmueble está protegido mediante declaración como monumento, pero aún carece de entorno delimitado. Ha sido sometido únicamente a intervenciones parciales de conservación, frente a evidentes necesidades, muy generalizadas en el inmueble y sus bienes muebles. A pesar de las publicaciones existentes es un edificio mal conocido en cuanto monumento por la ciudadanía, y demanda que las investigaciones e intervenciones profundicen todavía más en sus rasgos y valores patrimoniales.

\section{Palabras clave}

\section{Palacio de San Telmo}

Sevilla

Patrimonio inmueble

Proyecto de obras

Fuentes documentales

Exposición Hispano-Americana

Siglo XX

Seminario Metropolitano
Mandan desde principios del pasado siglo las nuevas necesidades eclesiásticas, sin que en ningún caso se produzca un proyecto global o en continuidad, al modo con que los Montpensier fueron adaptando el edificio a sus requerimientos de "segunda corte", fundamentalmente de la mano de Balbino Marrón. La rápida instalación del Seminario tras la firma de la escritura de propiedad implica reformas. El patio norte se subdivide mediante una estructura cruciforme, pensada para dormitorios; así como se llevan a cabo abundantes particiones en la planta principal, en buena medida para aulas, dentro de la estructura de crujias y adaptándose a los volúmenes existentes. Por el contrario, se eliminaron algunas divisiones en los torreones. Se trata de una labor realizada por Juan Talavera de la Vega, arquitecto ya presente en la fase previa de residencia de los Montpensier.

Debe tenerse en cuenta que las modificaciones decimonónicas con los Montpensier cuestionaron relativamente el hecho de que San Telmo fue en origen un edificio concebido para la enseñanza (siempre de varones) y la residencia de sus efectivos docentes y discentes. Por lo que se entendió en su momento que debía ser receptivo a las necesidades y usos del mismo como Seminario contemporáneo. 


\section{$078-079$ \\ Criterios \\ San Telmo, siglo XX: el palacio como Seminario Metropolitano \\ PH51 - Diciembre 2004}
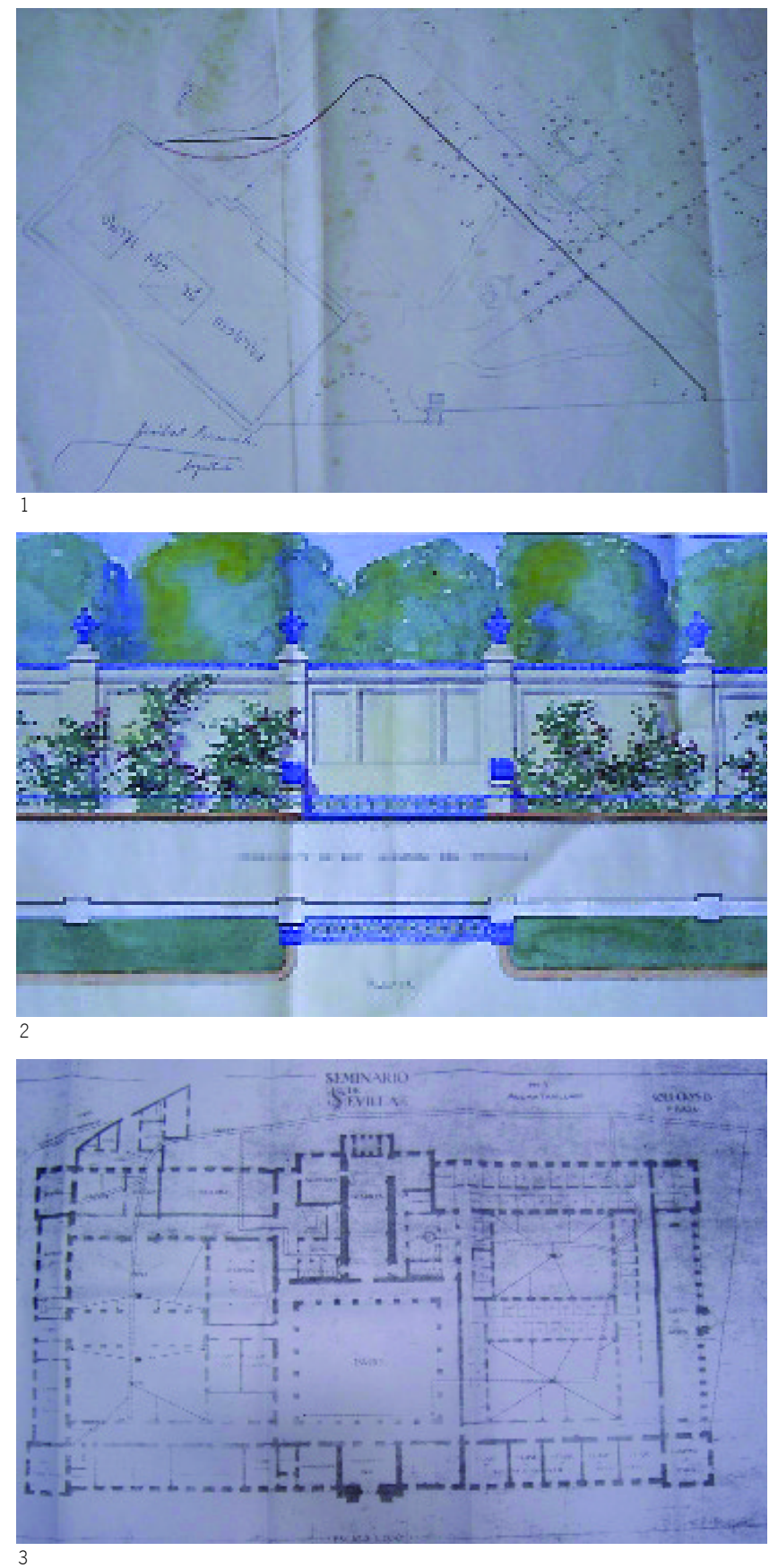

\section{Un destino en crisis}

Sin embargo muy pronto, con el cardenal Enrique Almaraz, ya no parece apto para tal finalidad y se establece una estrategia con objeto de demostrarlo. Se pretexta falta de funcionalidad e insalubridad, incluyendo informes médicos.

Francisco Navarro López, médico del Seminario General y Pontificio, el 6 de junio de 1921 libra un certificado por el que concluye
1. Aníbal González: Delimitación del jardin de San Telmo y nueva alineación. Hacia 1924. Archivo General del Arzobispado de Sevilla (AGAS). Asuntos Despachados, legajo 503.

2. Acuarela anónima: Cerramiento de los jardines del Seminario. AGAS. Asuntos Despachados, legajo 503.

3. José María de Basterra y Emiliano Amánn: copia del Plano Seminario de Sevilla. Solución B. Planta Baja. 1926. Documentación anexa al Expediente de declaración del Monumento. Ministerio de Cultura. Archivo Central. C/87655/14bis.

que este centro no reune las necesarias condiciones higiénica para el objeto a que está destinado pues se producen numerosos casos de paludismo en todas las formas, también porque se observa una exageración en las afecciones bronco-pulmonares y que las aguas que lo surten del manantial de Santa Lucia provocan epidemias de fiebres tíficas y paratíficas que han obligado en ocasiones cerrar el establecimiento y suspender los estudios ${ }^{1}$.

Una carta del cardenal Almaraz, ya precomiado de Toledo, enviada desde Madrid el 13 de junio de 1921 al Deán y Cabildo de la Metropolitana de Sevilla, resume su juicio y actuaciones. El inmueble ha sido costoso (el seminario enajenado reportó 252.500 pesetas y la instalación inicial 282.822 pesetas), pero es que además, según el prelado, es un edificio ya viejo, que exige constantes reparaciones. En su misiva se insiste en la falta de condiciones higiénicas y de aquellas que la pedagogía tiene sancionadas para la debida formación religiosa e intelectual de los que aspiran al Sacerdocio. Se afirma entre otras cuestiones que la capilla es insuficiente. Incluso el entorno no parece adecuado: Los paseos públicos y edificios profanos que lo rodean... han de producir, y de hecho producen, faltas de observancia en la disciplina y grave detrimento de la formación religiosa y literaria ${ }^{2}$.

Estos documentos, entre otros, son reveladores de los pasos encaminados a su traslado a un seminario de nueva planta, hecho sancionado oficialmente desde el Palacio Arzobispal durante el pontificado de Enrique Almaraz (1907-1921). En buena medida se trata de un proceso indudablemente alentado con las expectativas de cambio urbano y dinámica constructora auspiciados con motivo de la futura celebración de la Exposición Iberoamericana y que tiene unos episodios previos ${ }^{3}$.

En 1910 ya hay una reunión en la Cámara Arzobispal para tratar de la adquisición por el Comité de la Exposición Hispano-Americana para propiedad de la ciudad de el edificio todo del Seminario o antiguo Palacio de S. Telmo, con sus jardines, abonando en cambio a la Iglesia de Sevilla la cantidad que tiene señalada previamente por dos peritos.... El posible destino del edificio para pabeIlón de la muestra internacional -y posteriores dependencias municipales- gravitaba en aquel momento. La reunión no lleva a acuerdos concretos en dicho sentido, sino que el Arzobispo escuchó las consideraciones de los reunidos, opuestas a la operación: o convenía ni parecía oportuna la enajenación y venta del edificio del Seminario, salvo siempre el mejor parecer del Prelado ${ }^{4}$.

El interés por el palacio y sus jardines no decae. En 1911 el ingeniero municipal Francisco Robledo traza un Plano para el emplazamiento de la Exposición Hispano-Americana ${ }^{5}$ que incluye los jardines de San Telmo y el palacio, con la reserva de la apertura de una posible calle, cuya posición siempre se mantendrá en planos futuros hasta convertirse en la calle Rábida.

En el ayuntamiento se abre el 15 de junio de 1914 un expediente firmado con motivo de la cesión de los jardines de San Telmo para 
la Exposición Hispano-Americana ${ }^{6}$, en este caso para su cesión provisional. Se generan documentos que avanzan cuestiones como que el Palacio y sus jardines se entregan para el bien de la Ciudad é interés público y que, por tanto, su ulterior utilización responderá siempre á ese fin primordial. 0 que El Cardenal Arzobispo de Sevilla por amor á ésta Ciudad y cumpliendo las obligaciones que le imponen las Leyes, consiente en recibir por el Palacio y jardines de San Telmo que cede á la Ciudad de Sevilla, un nuevo Seminario y la cantidad en metálico que á continuación se expresarán.

El proceso se encadena. En 1917 se considera la enajenación del inmueble en Rescripto desde la Sagrada Congregación de Seminarios y Estudios Universitarios, con solo dos condicionantes ${ }^{7}$.

En 1921 el alcalde y presidente del Comité de la Exposición Hispano-Americana, conde de Urbina, solicita al cardenal Almaraz se nos entreguen para dedicarlos a usos en bien de la Ciudad el edificio y jardines de San Telmo dedicados hoy a Seminario Pontificio, recibiendo en permuta un nuevo edificio para Seminario, como compensación ${ }^{8}$.

Para ello se procede a un estudio mediante encargo a Aníbal González, arquitecto del máximo protagonismo en la ciudad por aquellas fechas. Realiza en marzo de 1921 un anteproyecto inspirado en los seminarios Pontificio Romano, de Madrid, Rennes y Bayonne. La enajenación del palacio y los terrenos permitiría construir el nuevo seminario en el Cortijo de Maestreescuela, un ensanche proyectado justamente por el propio González -donde buscó crear nuevos referentes urbanos de arquitectura religiosa (basílica de la Milagrosa) y educacionales-, además de atender a otras necesidades de la archidiócesis. El solar pensado aparece a título orientativo, careciendo entonces de decisiones más precisas al respecto. Su coste es de 3.236.919 pesetas (edificio, cerramiento y solar). Se envía a Roma este anteproyecto de seminario para 300 alumnos, redactado por el arquitecto sevillano a instancias del Comité de la Exposición Hispano-Americana ${ }^{9}$.

Las alternativas particularmente más intensas en torno al proyecto se suceden tras el nombramiento del cardenal Almaraz como titular de la archidiócesis de Toledo y antes que cese en la de Sevilla. Este último hecho supone la llegada a Sevilla del cardenal Eustaquio Ilundain (1921-1937) y la posterior marcha atrás en la iniciativa de un nuevo seminario, apoyada en el informe de la nunciatura. Se argumenta desde la nunciatura en contra del proyecto (área libre en torno a la edificación de dimensiones reducidas, excesiva distancia a la catedral, etc.), en escrito firmado por parte de Federico, Nuncio Apostólico, con fecha de 28 de febrero de $1924^{10}$.

\section{Cambios en el entorno, transformaciones en su interior}

El intervalo 1921-24 transcurre pues, con complicadas negociaciones y definición de nuevas fórmulas, que sustituyen a la citada es- trategia que había culminado con el proyecto de Aníbal González. El destino del edificio queda confirmado, pero la dinámica transformadora en que se sumerge desde entonces se ve marcada por varios factores. Por un lado, la pretendida continuidad de su envolvente tradicional, cuadrilonga y con cuatro torres en los ángulos. Por otra, la asunción de importantes cambios en su entorno urbano y, básicamente, en el interior del inmueble.

La paralización del Ante-proyecto de Seminario para Sevilla se ve compensada con la acelerada transformación del entorno de San Telmo, que se convierte en el paso siguiente: hasta 1929 se llevan a cabo reformas en los jardines y diversas tentativas de trazado de la calle Rábida, relacionadas con la parcial enajenación de los jardines del palacio.

El propio Anibal González interviene inicialmente en estas cuestiones, firmando un plano con la históricamente conflictiva delimitación de la curva en calle Palos ${ }^{11}$. Pero luego se produce una multiplicidad vacilante de decisiones y de autores, hasta que se cierra la larga operación segregadora, que planteó tanto la cesión temporal como la venta. Trazada la calle Rábida (calle Nueva), resuelta la curva de Palos de la Frontera (calle del Foso, ya discutida en el célebre pleito dieciochesco), y acotados los jardines del palacio a su dimensión definitiva, el dinero resultante de la operación faculta a la institución eclesiástica para acometer la reforma de su inmueble.

La cuestión del cerramiento de los jardines surge entonces. Aníbal González debió aportar ideas, luego hay un encargo a Aurelio Gómez Millán (arquitecto que también firma un trazado con el tema de la calle) ${ }^{12}$. Se abandona la imagen de la verja de hierro colado que introdujera Balbino Marrón sustituyendo a la tapia que de la Huerta de Santelmo da al Paseo del Río (trazas de 1847) ${ }^{13}$, en beneficio de la opacidad muraria.

En 1925 se trata desde la Exposición Ibero-Americana de cerrar la segregación, manifestando el interés del Comité y de la corporación municipal de llegar á la compra de los jardines de San Telmo en la parte que resulta segregada del Palacio después de la apertura de la nueva via y al objeto de poder ampliar los jardines del Parque de María Luisa ${ }^{14}$.

El 22 de diciembre de 1925 se envía el Rescripto 706/25 de la Sagrada Congregación de Seminarios que autoriza para enajenar una porción del parque (algo más de $62.000 \mathrm{~m}^{2}$, restando 19.000 ó 20.000 en poder del Seminario), percibiéndose con la venta efectuada en 1926 la cantidad de 1.700 .000 pesetas. Parte del dinero obtenido se destinará a obras y reparaciones y el resto constituye un capital permanente cuyos intereses se invertirán en conservar el edificio ${ }^{15}$.

Las obras se hacen con la Sociedad Anónima de Construcciones. En julio de 1926 se pagan al Arquitecto de Bilbao Sr. Basterra, a cuenta de sus respectivos honorarios la cantidad de 3.000 pesetas. En mayo de 1927, 12.000 pesetas son Pagadas a los Arqui- 


\section{$080-081$ \\ Criterios \\ San Telmo, siglo XX: el palacio como Seminario Metropolitano \\ PH51 - Diciembre 2004}

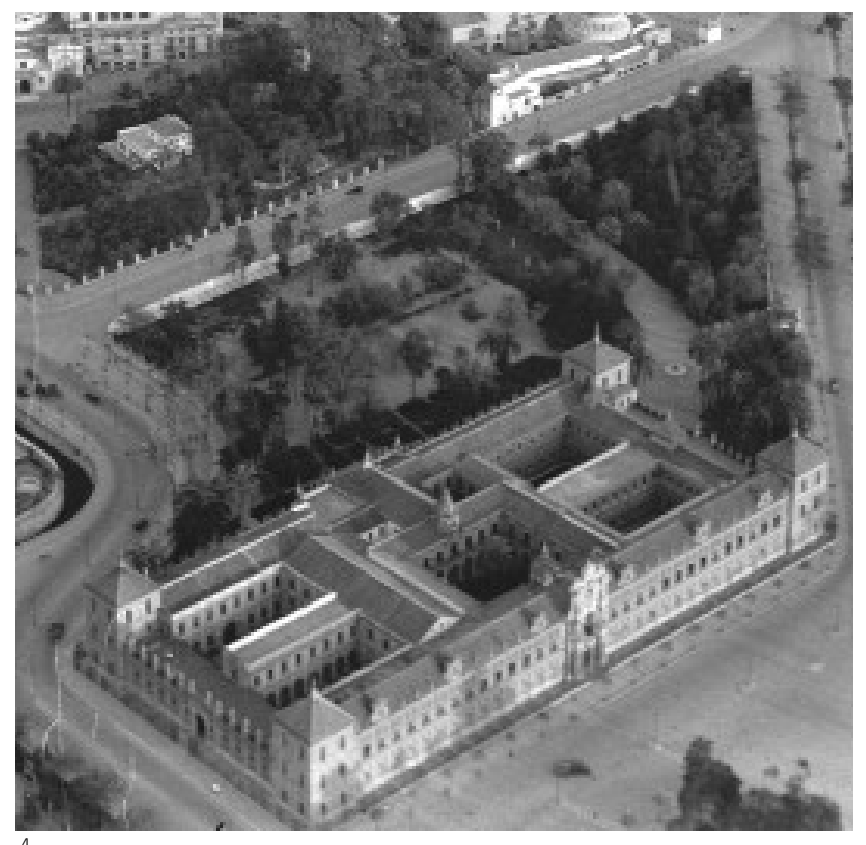

tectos de Bilbao, Sres. Basterra y Amann, por liquidación de honorarios como remuneración de sus trabajos de formación de planos y dirección superior de las obras, esta cantidad se anticipa del fondo de reserva diocesano para ser reintegrada de los del Seminario. La inversión total se elevó a 853.365,89 pesetas. Las cuentas de las obras de reforma y adaptación definitiva del Palacio de San Telmo para Seminario, de José María Basterra y Madariaga se cierran en abril de $1928^{16}$

Se acude pues, tras desprenderse de parte de los jardines, a la modificación interior: el dinero de la venta se dedica fundamentalmente al proyecto de José María de Basterra (1926), profesional que previamente habia colaborado con el cardenal Ilundain en Orense. Era una figura bastante presente en la arquitectura religiosa vizcaína (torre de Begoña, iglesias en el ensanche de Bilbao...), o en los edificios docentes de Deusto (éstos proyectados en colaboración con figuras como el marqués de Cubas o Emiliano Amánn ${ }^{17}$ ), etc. Este arquitecto no ha alcanzado reconocimiento como un creador significativo, desempeñando más bien su oficio con eficacia dentro de una coyuntura y un ambiente muy específicos, auspiciado su trabajo por la burguesía y el clero bilbaínos de principios del XX.

El plano firmado por Basterra y Amánn en 1926 (solución B, Planta Baja -la planta alta la conocemos por la publicación de C.E.A. en la revista Arquitectura ${ }^{18}$ ) se ha localizado con redelineado para alcantarillado ${ }^{19}$. Este plano conocido de su intervención y los resultados evidentes de su obra hablan de una regularización del edificio que pretende imponer al inmueble la idea de un orden aparentemente más claro, pero también más rígido, tanto en la zona norte como en la zona sur. Su intervención puede resumirse en la búsqueda de una cierta simetría supuestamente obligada -eliminando en la zona norte del apeadero su esquema cruciforme, de
4. Foto aérea del palacio, tras la reforma de Basterra, tomada desde el Zeppelin. 1929. Archivo Sánchez del Pando. Fototeca Municipal de Sevilla. Signatura. SP4/V-SF/77

5. Patio sureste que muestra la intervención de Basterra. 2003. Foto: Eduardo Mosquera

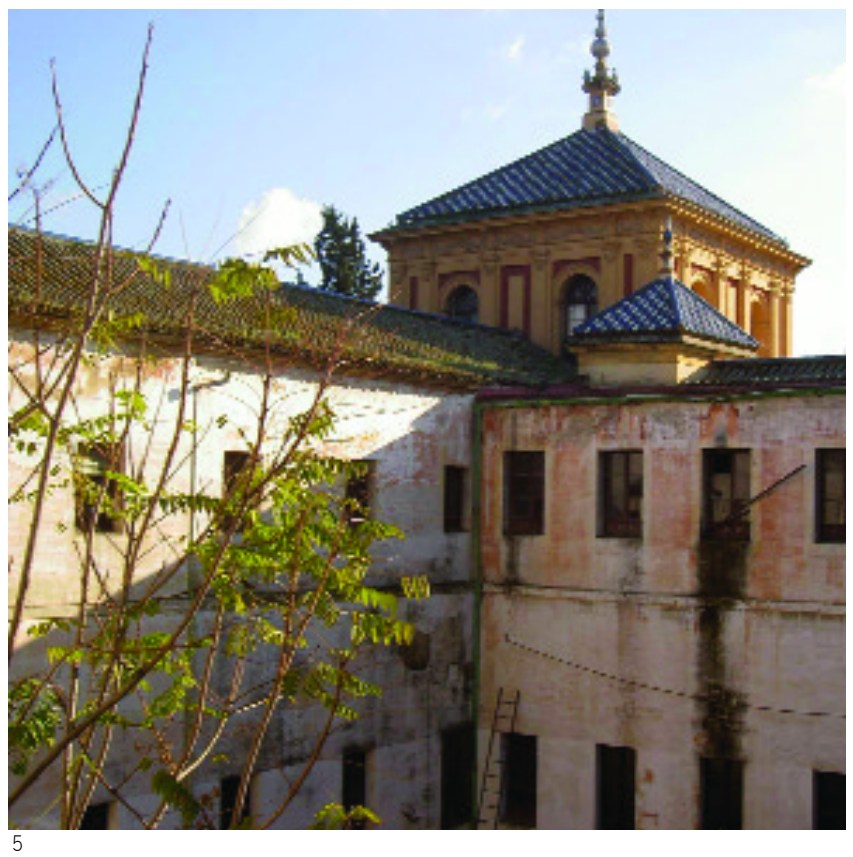

tiempos de Talavera-, dotando al complejo de una mayor escala física en llenos y vacíos. Pero, significativamente, la operación -basada en la fría solemnidad de su escala, propia de la formación académica de Basterra y Amánn- propicia además, de forma contradictoria, una fragmentación interior, a veces a escala muy menuda, como paso previo a la que se llevará a cabo en la segunda mitad del XX. De hecho, la fragmentación produce no pocas distorsiones, como unas circulaciones mal definidas, a pesar de esa aparente y decidida intención regularizadora.

Los cuerpos de edificación que levanta Basterra en la zona sur aplican líneas simples, de clara y monótona austeridad, algo que estaba presente en el espíritu del proyecto de Aníbal González para el nuevo Seminario, pero que se convierten mediante una esquemática pauta racionalizadora en fachadas secundarias, peyorativamente de patio, en San Telmo. Basterra, demolidos patios y crujías barrocos, no entiende el papel activo de los patios como vacíos generadores de arquitectura. Practica simples envolventes para un programa densificador -con escasas permanencias históricas interiores, como el muro de la antigua ala este de dormitorios- donde sus nuevos patios ahora son simples residuos, restos que quedan de sus ocupaciones, sin ningún protagonismo arquitectónico. Sus estructuras, en buena medida de nueva planta sobre intensos vaciados en sectores históricos del primer San Telmo, quedaron convertidas en acompañantes discretas y secundarias, alejadas de la brillantez de algunas de las intervenciones en el edificio propias de siglos pasados, pero alcanzaron sin embargo un peso notable en la configuración interna del palacio.

Mientras, prosigue el trabajo en el contexto inmediato del inmueble, bastante complejo de esquematizar por los innumerables protagonistas que concurren. Basta recordar el plano del ingeniero de 
6. José Galnares Sagastizábal: Proyecto de Reforma Seminario. Planta parcial, alzado de escalera y detalles. 1962. Fondo Documental del arquitecto José Galnares Sagastizábal, en Archivo Profesional del arquitecto Juan Fernández Carbonell.

7. Vista de uno de los patios de las camarillas ejecutadas por José Galnares. 2003. Foto: Eduardo Mosquera

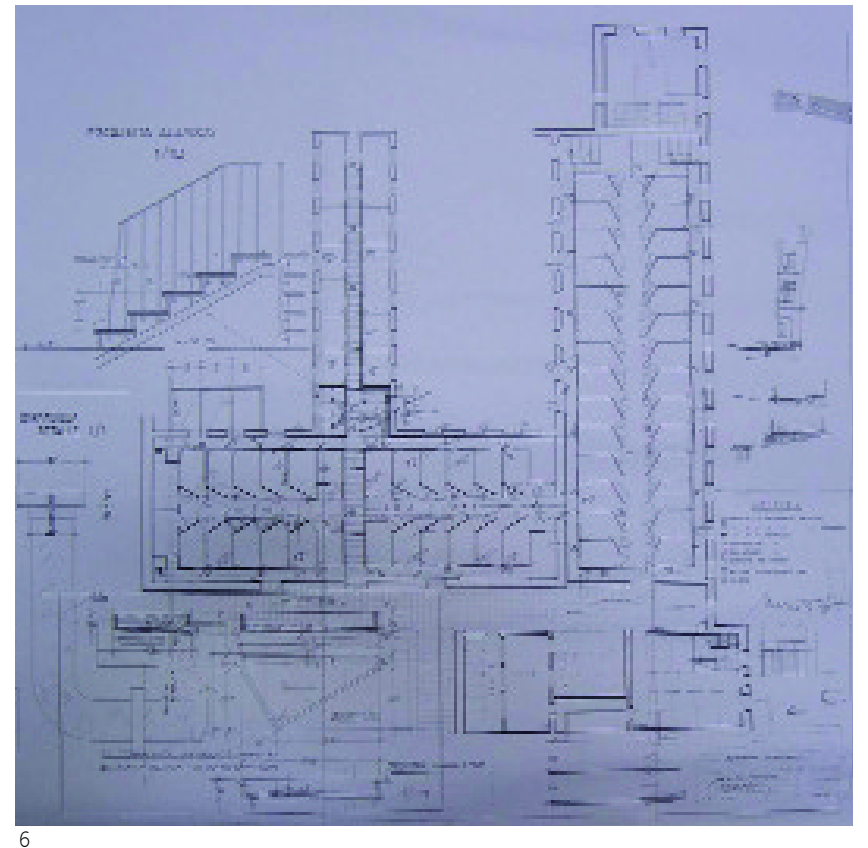

Caminos Antonio Izquierdo y Gómez del 1 de mayo de 1926 de emplazamiento de la Exposición. Hay uno del mismo autor, de 3 de febrero, sobre los viales en torno a San Telmo y otro de 22 de abril que sirvió para efectuar la obra ${ }^{20}$, debiendo mencionarse el Proyecto de formación de calles en Los Jardines de San Telmo, de Antonio Izquierdo, con movimiento de tierras por Rafael González, y certificación de abril de 1926.

Otras obras en los jardines de San Telmo, certificadas ese mismo mes, fueron dirigidas por Aurelio Gómez Millán, con la Empresa General de Construcciones. Llevan fecha de 27 de abril de 1926. Incluyen $119,80 \mathrm{~m}$. de mampostería, con excavación y relleno, enfoscado y enlucido, en la trasera del palacio. Prosiguen los trabajos en 1927 con el arquitecto Pedro Sánchez Núñez, mientras que Eduardo Carvajal es el ingeniero que da los vistos buenos por la Exposición. En junio y agosto de 1927 se documenta la apertura de calle con el arquitecto Vicente Traver y Eduardo Carvajal. La urbanización de los jardines de San Telmo posee un proyecto fechado en el 2 de agosto de 1927. Fue una obra dirigida por el ingeniero Eduardo Carvajal y Acuña, adjudicada el 1 de septiembre a Emilio Panduro. Su certificación es de diciembre de $1927^{21}$.

San Telmo, intervenido por Basterra y con la calle trazada, se ve reconocido en su nueva plenitud en imágenes como la foto aérea tomada por el dirigible Zeppelin, con motivo de su llegada a la Sevilla del 29 , donde el palacio aparece convertido en una referencia urbana previa a los espacios expositivos, con los que se le quiere relacionar desde un punto de vista paisajístico ${ }^{22}$.

El artículo publicado el mismo año en el número 119 de la revista Arquitectura por C.E.A. subraya la valoración que adquiere el edificio, tras los ejercicios historiográficos pro barroco de Schubert ${ }^{23}$, entre

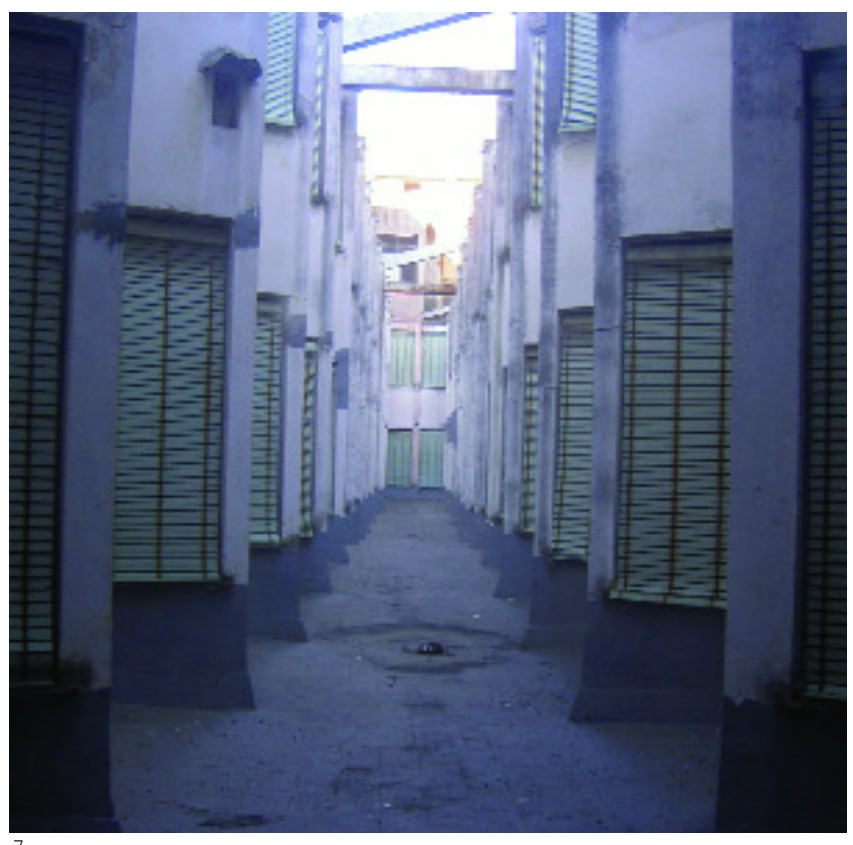

otros, y el interés regionalista 0 , más genéricamente tardo académico, por el neobarroco y su conexión con las esencias barrocas como cualificado tiempo pasado de la arquitectura sevillana.

La década siguiente no registra cuestiones de relevancia. Existe alguna constancia documental sobre el encargo en 1946 al arquitecto Aurelio Gómez Millán de la elevación del cerramiento posterior de los jardines ${ }^{24}$. Este arquitecto ya fue firmante previo de alguna de las soluciones de trazado de la calle Rábida y se personará, según el diario ABC del martes 8 de julio de 1952, en el Seminario para apreciar el alcance de las pérdidas tras el incendio sufrido ${ }^{25}$.

\section{El incendio de 1952}

En 1952, en tiempos del cardenal Segura y Sáenz (1937-1954), se produce un incendio de tristes consecuencias para su patrimonio, particularmente graves en el caso del documental y bibliográfico. El cardenal Segura, a través del Boletín Oficial Eclesiástico del Arzobispado de Sevilla indica que ha sido presa de pavoroso incendio nuestro Seminario Mayor Diocesano. Expone el alcance: ha afectado a la crujía de fachada, desde la gran escalinata monumental, cuya cúpula se ha desplomado en su casi totalidad, hasta el torreón angular de la enfermería, alcanzando las ruinas una longitud de 51 metros $^{26}$. El rectorado, el departamento contiguo a la biblioteca y el torreón se vieron singularmente afectados.

La tasación de los daños eleva su cuantía a 4.486.693,25 pesetas $^{27}$. El cardenal apela a la colaboración de Regiones Devastadas y del Ministerio de Educación Nacional haciendo valer, erróneamente, que el edificio está declarado monumento nacional ${ }^{28}$. El inmueble requiere la intervención restauradora, especialmente sig- 
$082-083$

\section{Criterios}

San Telmo, siglo XX: el palacio como Seminario Metropolitano

\section{PH51 - Diciembre 2004}

8. José Galnares Sagastizábal: Planta de cubiertas? Consolidación de cubiertas en el palacio de San Telmo. 1969. A.H. FIDAS, Expediente 099986

9. Escuela Universitaria "Cardenal Spínola". Planta baja. (Antonio Delgado Roig-Atberto Balbontín, 1972) A.H. FIDAS. Fondo Antonio Delgado Roig-Alberto Balbontín, caja 1218, exp. 18, copia
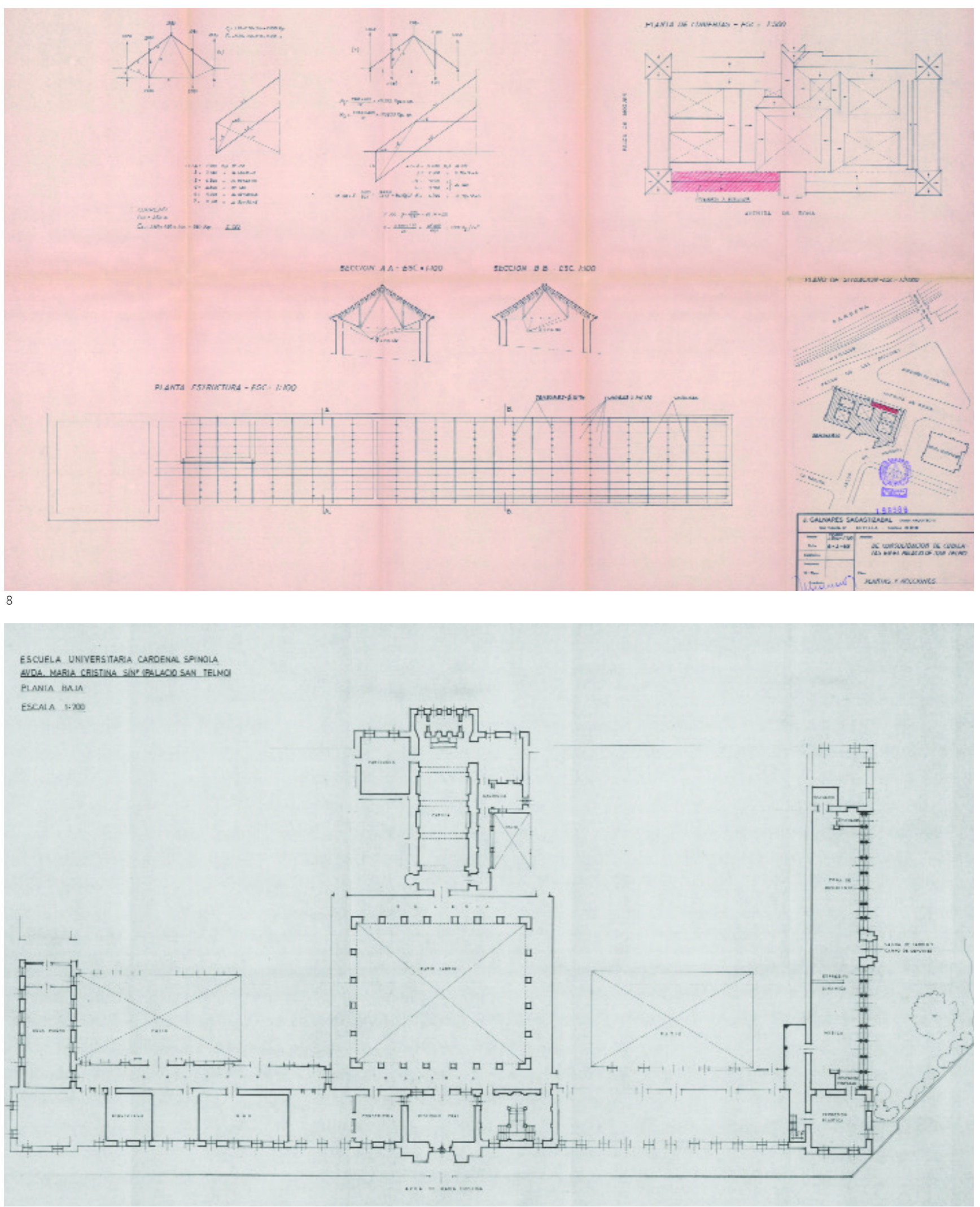
nificativa en la zona de la escalera; pero esta actuación no está documentada arquitectónicamente por el momento. Se sabe que la comisión creada al efecto encarga la restauración, la primera propiamente dicha que sufre el inmueble, al arquitecto Antonio Illanes del Río ${ }^{29}$. Se aprecia en su intervención un deseo de reconstruir figurativamente dicho espacio en su fase inmediata. Actúa recuperando una decoración añadida sobre las nervaduras que delimitan los lunetos y hojas de la plementería que cierran la bóveda encamonada y la linterna ciega con las que se remata el vacío de la escalera. Idéntico matiz se aplica a los añadidos ornamentales del entablamento que discurre por la coronación de los muros, bajo la citada bóveda o las arquerías que soportan la escalera ${ }^{30}$.

\section{La disposición de las camarillas}

La expansión del Seminario y la introducción de otros usos en San Telmo propiciarán la construcción de las llamadas camarillas en 1962. Es el momento en que penetra desprejuiciadamente en el edificio una figuración moderna, basada en la aplicación acrítica y descomprometida de algunos de sus presupuestos formales, y que se ve acompañada de materiales y sistemas constructivos con una lógica propia de dicho talante y alejada de las características del edificio, que será impuesta sin efectuar las adecuadas transiciones.

El aprovechamiento de los volúmenes vaciados y reocupados, más los nuevos remontes que sobresalen en el juego de cubiertas del edificio, se efectúan ahora con una práctica de optimización de espacios, para un viejo palacio utilizado al límite de sus posibilidades, marcando el sesgo que San Telmo adquiere en una época de crisis en la cultura arquitectónica local. Su autor, José Galnares Sagastizábal, arquitecto y académico, tras sus avanzadas incursiones en la arquitectura moderna, compagina -en la época de crecimiento económico y auge constructor- por un lado una práctica arquitectónica de nueva planta, entonces menos tensa que en su interesante trayectoria temprana, desde el punto de vista de la cultura arquitectónica contemporánea. Sin embargo, simultáneamente, el prestigio alcanzado le granjea importantes encargos de intervención en los años sesenta y setenta del pasado siglo sobre el Patrimonio Histórico sevillano (Museo de Bellas Artes, Museo Arqueológico, Panteón de Sevillanos Ilustres en la Anunciación, escuela de Bellas Artes en la antigua Universidad Literaria...), algunos incluso envueltos en la polémica ${ }^{31}$.

En 1962 este arquitecto realiza las camarillas sobre buena parte de la zona norte del edificio, generando una $L$ en dos frentes del patio ${ }^{32}$. En un primer nivel se disponen 72 camarillas y 58 en la segunda planta. En la planta tercera se sitúan 43 camarillas. Son crujías cubiertas a un agua mediante faldón inclinado, acabado con teja árabe. Este hecho implica la remoción de elementos históricos para efectuar una notoria modificación de la volumetría del edificio, con emergencias insólitas, contra la lógica de sus cubiertas ${ }^{33}$.

Los departamentos aparecen dispuestos formando una quebrada con un patio lineal central al que dan jardineras individuales. El sis- tema impuesto al edificio se basa en la aplicación sobre sus fábricas murarias de estructura metálica a base de dos tipos de cerchas, con perfiles normalizados, utilizados con su sección de origen y en algunos casos formando cajones. Entre los detalles arquitectónicos diseñados que se han localizado debe citarse el de la barandilla de la escalera o las jardineras de los patios. La obra corrió a cargo de la empresa Rober. Años más tarde mantendrá su posición de arquitecto de San Telmo para efectuar alguna restauración.

En los años sesenta se perpetra asimismo la destrucción de buena parte de los deteriorados jardines, para la ubicación del campo de fútbol.

\section{San Telmo, monumento: declaración y restauración}

Las obras efectuadas y la reorganización del Seminario en 1966 no ocultan el hecho de que se produzca, con el cardenal Bueno Monreal (1954-1982), la apertura de conversaciones -en 1967- para convertir el edificio en Parador de Turismo, con la opinión favorable del entonces director general de Arquitectura, Miguel Ángel García Lomas. La declaración como monumento histórico artístico de abril de $1968^{34}$, que incluye a sus jardines, supone hacer oficial la valoración efectuada por el historiador Antonio Sancho Corbacho y que fue asumida por las academias de Bellas Artes de Santa Isabel de Hungría y de San Fernando. En el caso de la sevillana, a partir del acuerdo conjunto de la Comisión Provincial de Monumentos y la Academia de 28 de julio del año anterior ${ }^{35}$. Hubo otra reunión de la Academia para tratar el tema y resulta interesante comprobar que José Galnares es el único arquitecto académico presente en las dos sesiones que se celebran al respecto de la declaración ${ }^{36}$. Y luego la cuestión se ratifica por la academia madrileña, en sesión celebrada el 6 de noviembre de 1967, donde fue ponente el historiador valverdeño Diego Angulo. Se detiene gracias a esta medida nuevamente otro proceso de enajenación del edificio. El 22 de marzo se comunica al cardenal arzobispo que se va a proceder a la declaración, aprobándose el 6 de abril.

San Telmo como patrimonio declarado propicia la vía restauradora. José Galnares redacta un primer proyecto en marzo de 1969 no ejecutado, del que hay dos versiones de su apartado económico, según muestran los cambios de presupuesto ${ }^{37}$ : uno quizá por encargo únicamente del arzobispado y otro presupuesto con honorarios para obra oficial, al intervenir ya el Ministerio de Educación y Ciencia ${ }^{38}$. Galnares remite el 29 de octubre a Madrid, a la Comisaría de Patrimonio Artístico, dos ejemplares del proyecto de Consolidación de Cubiertas en el Palacio de San Telmo (Seminario Diocesano). Se proyecta la demolición de la cubierta de las crujías de fachada entre la portada y la torre noroeste. Se introducirá una cubierta con estructura inclinada a dos aguas y forjado horizontal, todo a base de perfiles metálicos y bovedillas prefabricadas. Los faldones se cubren con teja árabe y el forjado con solería de ladrillo de $14 \times 28 \mathrm{~cm}$. El forjado se hace a nivel de ti- 


\section{$084-085$ \\ Criterios}

San Telmo, siglo XX: el palacio como Seminario Metropolitano

\section{PH51 - Diciembre 2004}

rantes para pasar del torreón a la terraza del reloj y trasteros ${ }^{39}$. Toda la documentación gráfica se expresa en un único plano que incluye los funiculares para dimensionar los perfiles de las cerchas, correas, etc. El PEM según el arquitecto asciende a 830.359,17 pesetas, modificándose en noviembre por el Jefe de Sección a un presupuesto total incluyendo honorarios de los facultativos de 800.657,51 pesetas.

El segundo proyecto, titulado Proyecto de Obras en el Palacio de San Telmo-Sevilla, con ligeras matizaciones respecto al previo, en la misma zona del edificio, se realiza bajo encargo ministerial ${ }^{40}$. Mantiene sus rasgos de intervención con tecnología constructiva contemporánea en sus aspectos estructurales y algunos de sus acabados, sin prestar especial atención a la convivencia con la rica cultura material del edificio. Su lacónica memoria se transcribe completa: Las obras proyectadas consisten en: Desmonte de cubierta de teja arabe y de los elementos de madera de la estructura sustituyendolos por otros metálicos para la construcción de forjado horizontal del piso. Sevilla, 12 de Noviembre de 1973. Las cerchas, formeros y correas, a base de perfiles normalizados, se mantienen pero

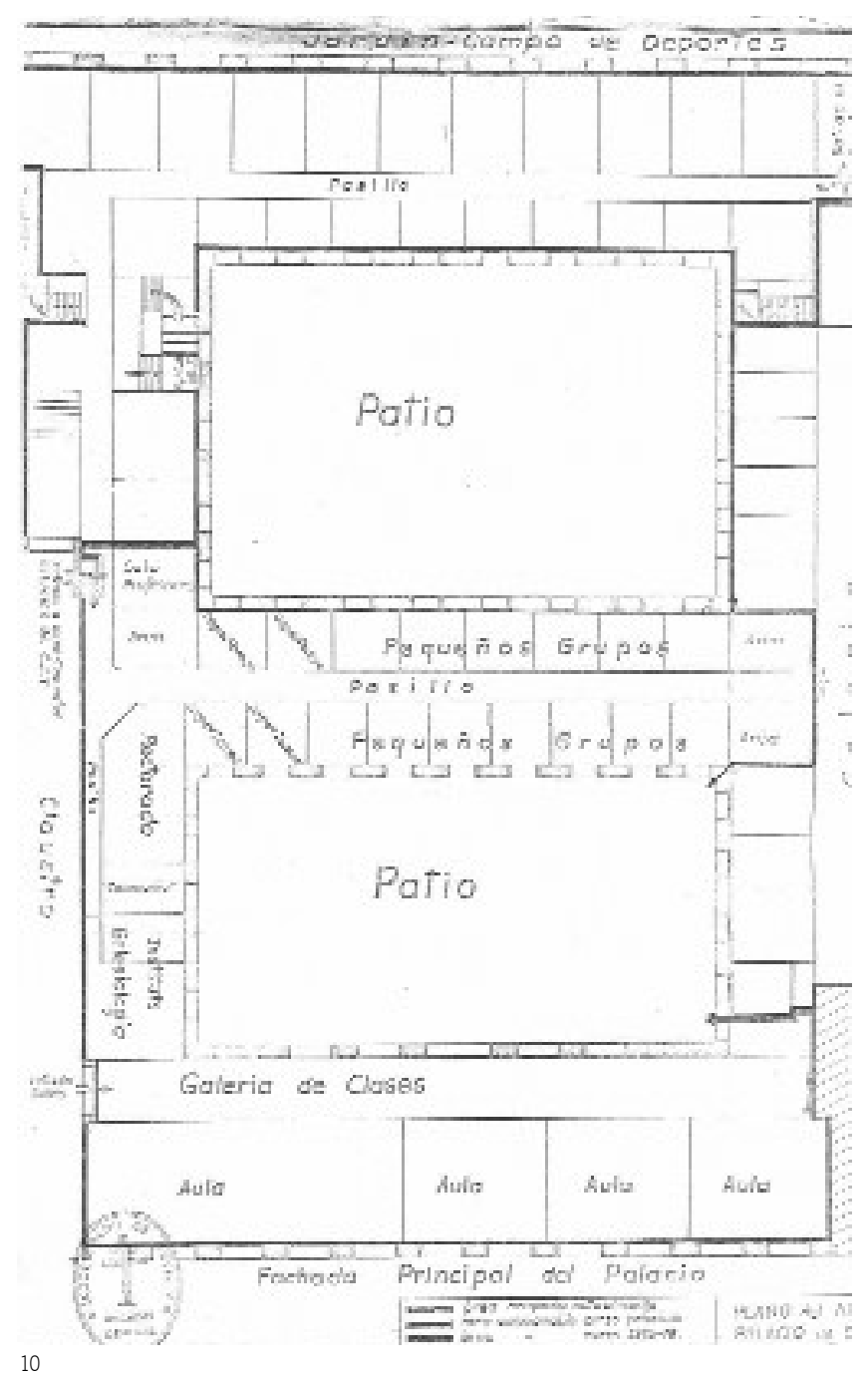

10. Anónimo: Plano sesgado, con la reubicación de algunos usos. 1974. AGAS, Archivo Personal del Cardenal Bueno Monreal, legajo 19 con cambios apreciables en las mediciones de determinadas partidas respecto a 1969. El presupuesto es del mes de abril de 1973 y suma 1.116.256,13 pesetas. También incluye un único plano. Consta una diligencia de aprobación de 29 de marzo de 1974.

Tras las obras de sustitución de la estructura de parte de las cubiertas, propiciadas en su día por el seísmo de febrero de 1969, el edificio seguía manteniendo bajo cuestión su continuidad como Seminario. De hecho, al hilo de las obras de restauración, en 1974, la Universidad Hispalense oferta su adquisición para sede universitaria.

\section{Usos y nuevas propuestas}

El paso del tiempo arroja un balance de menos seminaristas, pero el edificio se mantiene en carga: además de Seminario y de haberse empleado parte de él como improvisado hospital para los heridos de la guerra de África, en la segunda mitad del XX Ilega a servir en simultáneo de residencia de sacerdotes, de Centro de Estudios Teológicos (dependiente de la Facultad de Teología de la Cartuja de Granada), de Escuela Superior de Magisterio (luego Escuela Universitaria de Formación del Profesorado de EGB) "Cardenal Spínola", de Escuela Diocesana de Teología para Seglares, o de residencia de religiosas de la Caridad de Santa Ana (que durante años asisten al Seminario).

Se llega así a proyectos de refuncionalización, como el del arquitecto y académico Antonio Delgado Roig, en 1974, a base de meras particiones, en la sala de las columnas, por ejemplo, para aprovechamiento intensivo con usos fragmentarios. Existe un encargo de Reconocimiento y certificación del Palacio de San Telmo para certificar que los locales de la Escuela del Profesorado de Educación General Básica "Cardenal Spínola" reúnen las necesarias condiciones de seguridad $^{41}$. El 8 de abril de 1974 realiza Delgado Roig un informe sobre adaptación de la zona sur del palacio. Sin modificaciones apenas en planta baja y primera, exceptuando zonas de planta primera antes utilizadas para dormitorio de seminaristas en el patio de Basterra, y que ahora alojan el Departamento de Ciencias y un aula grande, previéndose nuevas reformas para adaptaciones destinadas al curso entrante. También existe una memoria del Proyecto de adaptación de una parte del edificio del Palacio de San Telmo para Escuela del Profesorado de E.G.B. Cardenal Spínola, con numerosas correcciones y un texto denominado Modificación del escrito. En los textos se producen referencias a planos del que se ha localizado uno de planta baja ${ }^{42}$.

La ocupación y uso del edificio no propician ni la aparición de la arquitectura ni tampoco su consideración patrimonial en función de sus valores. En ese momento, previo al curso 1974-75, se realiza el plano sesgado como expresión de la crisis entre determinados seminaristas y la jerarquía, que no es sino un mero esquema de relocalización de dependencias ${ }^{43}$.

Los últimos derroteros y restauraciones se efectúan con la administración de Cultura hacia la salida del Seminario. El intento de 
adquisición por la Diputación en 1980 y luego el logro alcanzado definitivamente por la Presidencia de la Junta de Andalucía cierran esta página, mientras en 1982 comienza otro capítulo arquitectónico con la labor en el edificio del arquitecto Guillermo Vázquez, que incluye también interesantes descripciones y análisis del inmueble por su parte, o publicaciones de José María Vázquez Soto o Teodoro Falcón, entre otros ${ }^{44}$.

\section{Conclusiones: valores patrimoniales del siglo XX, en su etapa como Seminario}

En el pasado siglo, tras la instalación del Seminario, se producen escasas aportaciones como tales para el enriquecimiento arquitectónico del edificio, a pesar del fuerte nivel de intervención experimentado en las décadas analizadas (años 20-años 70).

Dentro de los aspectos negativos, subrayaremos que se auspicia la fragmentación a veces exasperante del inmueble, abundando las actuaciones impositivas: se pierde un orden equilibrado, obtenido en el siglo XIX, particularmente en la zona norte.

Basterra, al pretender manejar una escala solemne que pretendía la racionalización de los espacios resultantes, introduce una arquitectura modular, limpia en ocasiones, pero monótona en ausencia de elementos figurativamente significativos. Con la intervención de Basterra, la más extensa, se pierde, en beneficio de una mayor sencillez, una escala doméstica que se conjugaba con la escala grande, derivada del primer San Telmo, y que había resistido en el tiempo. El arquitecto vasco promociona una imagen de patio: arquitectura aparentemente contenida y racional, de fachada secundaria. No construye unas fachadas interiores propiamente, como históricamente se había venido haciendo. En su proyecto no es entendido el edificio dentro de la arquitectura sevillana, dentro del sesgo de la aportación de las fases primigenias, algunas con indudable valor destruidas con su intervención, y que son propias de una arquitectura de decantación histórica: el hecho representa pues una clara anomalía. El espacio de los patios carece entonces del debido protagonismo: es un residuo, no es un generador de arquitectura.

Otra cuestión relevante es la pérdida del rango parcelario: la dinámica urbana más ágil se produce a sus espaldas. Esto propicia que el jardin, ahora bien cerrado, quede presto a su conversión en campo deportivo. Sus cualidades históricas sin embargo se perciben todavía en buena parte de la planimetría del siglo XX.

La búsqueda del aprovechamiento del inmueble conduce a posteriores operaciones intensivas, con más sustituciones por estructuras de nueva planta, como las camarillas de José Galnares, de 1962, construidas con técnicas y materiales ajenos, con una figuración que no casa con la entidad del edificio, cuya entidad histórica se ignora en beneficio de una intervención autónoma. Quizá el rasgo figurativo más singular es la ajena y prescindible escalera que les da acceso.
La intervención restauradora en los setenta, con materiales y técnicas modernas, resulta ajena a su sentido constructivo. Curiosamente no se reivindica nunca este aspecto, ya conculcado por el propio José Galnares con las camarillas, pues parece asumido por corrientes restauradoras que no han reflexionado suficientemente sobre su coherencia con las fábricas históricas. No se documenta el estado previo, hecho extensible a todas las actuaciones contemporáneas analizadas.

Las últimas fragmentaciones con Delgado Roig expresan un estado de pura supervivencia. El orden vital de los ocupantes del edificio se manifiesta cada vez más ajeno al propio edificio, que queda enmudecido y pasivo. Esa pasividad y disponibilidad han marcado profundas huellas y han dificultado, cuando no impedido, la comprensión de su dimensión patrimonial.

\section{Elementos contemporáneos de interés}

La continuidad del debate del XVIII sobre la actual calle Palos y la solución "definitiva".

El comienzo de la valoración patrimonial del inmueble, en una época crucial del mismo (años 20) más allá de una conciencia académica del estudio del barroco (recordar la historiografía de la Arquitectura española al respecto: Schubert, Lampérez...).

Desde la segunda mitad del XIX el edificio se corresponde, ya no con el espacio de la Puerta de Jerez y el arranque del camino (dentro de la serie de proyectos ilustrados que incluyen el sector del salón del Cristina), sino con el desarrollo de una lógica urbana de crecimiento de la ciudad hacia el sur: cada pieza es una manzana edificada, más su espacio verde o jardín, de respeto o de expansión, siguiendo el ejemplo de San Telmo y su mutilado espacio (Fábrica de Tabacos, Alfonso XIII y tantos elementos del 29, entre otros...).

Los principales planes de ensanche cuentan con San Telmo, desde Velázquez Bosco (1902) o el plano de 1911 para la Exposición Hispano-Americana de Rodríguez Caso, Quesada y el conde de Aguiar. El edificio es una pieza en el arranque del trazado del crecimiento sur de la ciudad y un protagonista en los nuevos conceptos de ciudad que se manejan, tenido como frente cualificado, como charnela urbana entre el vacío de la Puerta de Jerez - puente de San Telmo y las nuevas ordenaciones hacia el sur. Aparece pues el edificio dentro de una cultura urbana que desborda al propio San Telmo, ya construido y plegado sobre sí mismo y sus intereses inmediatos e internos, pero una cultura que pretende integrarlo.

Las intervenciones en el edificio han subrayado su autonomía como objeto, pero han puesto de manifiesto la necesidad de rescatar una relación más eficiente con su entorno de referencia. No sólo en el sentido de controlar la evolución del entorno (grandes piezas, grandes manzanas personalizadas) sino de que deben volverse activos determinados valores históricos y de paisaje. 
$086-087$

\section{Criterios}

San Telmo, siglo XX: el palacio como Seminario Metropolitano

\section{PH51 - Diciembre 2004}

${ }^{1}$ Archivo General del Arzobispado de Sevilla (AGAS). Asuntos Despachados, legajo 503 rojo, 05007 verde.

${ }^{2}$ Ibidem.

${ }^{3}$ Una documentada visión histórica que analiza los perfiles juridicos del traslado a San Telmo, los intentos de enajenación del edificio y sus jardines y los rasgos institucionales del Seminario se desarrolla en trabajos como el de Manuel Martín Riego: La formación intelectual del clero. El Seminario Conciliar de Sevilla (1831-1891). Sevilla: Caja Rural de Sevilla, 1894. 0 el más reciente de Alberto Ribelot Cortés: Vida azarosa del Palacio de San Telmo. Su historia y administración eclesiástica. Sevilla: Marsay, 2001. 2 vols.

${ }^{4}$ Acta de la reunión de los miembros de las Diputaciones de Hacienda y Disciplina del Semina rio General y Pontificio y el Sr. Arzobispo, de 22 de diciembre de 1910. AGAS. Asuntos Despachados, legajo 503

${ }^{5}$ Original conservado en la Gerencia Municipal de Sevilla.

${ }^{6}$ Secretaria Municipal de Sevilla. Negociado de Asuntos Especiales n²2. AHMS. Sección XVIII (EIA), caja 67.

${ }^{7}$ Según documento suscrito en Roma tras audiencia de Benedicto XV, del 29 de octubre de 1917. AGAS. Asuntos Despachados, legajo 503.

${ }^{8}$ Carta fechada el 1 de junio de 1921. AGAS. Asuntos Despachados, legajo 503.

${ }^{9}$ El proyecto se encuentra en AHMS. Sección XVIII (EIA), caja 68. Existe también documentación en el fondo de Anibal González custodiado en el Archivo de FIDAS, sign. EP 41/1.

${ }^{10}$ Copia de dicha carta, firmada por el cardenal llundain y enviada al Comisario Regio, en Archivo Histórico Municipal de Sevilla (AHMS).. Sección XVIII (EIA), caja 67.

${ }^{11}$ AGAS. Asuntos Despachados, legajo 503

${ }^{12}$ Se ha localizado en AGAS. Asuntos Despachados, legajo 503, una acuarela sin firma ni fecha, que pudiera ser de Anibal González o Aurelio Gómez Millán, pues se aproxima a lo ejecutado como cerramiento. La rotulación y el contexto documental donde se halla reafirman que debe ser precisamente de la época.

${ }^{13}$ Negociado de Ornato y Paseos, núm. 138. Localizado en AHMS. Documentación complementaria. Caja 449, Huertas de San Telmo y de Colón.

${ }^{14}$ Escrito dirigido al cardenal llundain el 21 de octubre de 1925. AHMS. Sección XVIII (EIA), caja 68

${ }^{15}$ Según decreto de 24 de junio de 1926 del cardenal Ilundain. AGAS. Asuntos Despachados, legajo 503.

${ }^{16}$ AGAS. Asuntos Despachados, legajo 503.

${ }^{17}$ Cfr. Arq. Basterra y Amánn: "La Universidad Comercial de Deusto". Arquitectura, 104, diciembre, 1927, págs. 435-439.

${ }^{18}$ C.E.A.: “El Palacio de San Telmo, en Sevilla”. Arquitectura, 119, marzo, 1929, págs. 83-94

${ }^{19}$ Anexo al Expediente de declaración del Monumento. Ministerio de Cultura. Gabinete. Archivo Central. C/87655/14bis.

${ }^{20}$ Este último plano posee signatura C-69/2 de la Hemeroteca Municipal de Sevilla.

${ }^{21}$ Planos y expedientes localizados en AHMS. Sección XVIII (EIA), cajas 67 y 68.

${ }^{22}$ Imagen custodiada en la Fototeca de la Hemeroteca Municipal de Sevilla. Signatura F/0010/04.

${ }^{23}$ Cfr., para San Telmo, Otto Schubert: Geschichte des Barock in Spanien. Esslingen a. N.: Paul Neff Verlag, 1908, págs. 193-195, especialmente; también el comentario en pág. 199. Trad. espa ñola: Historia del barroco en España. Madrid: Saturnino Calleja, 1924

${ }^{24}$ Nota de encargo con $n^{\circ}$ de Registro 23635, de 24 de octubre, a su favor, por cuenta de Santos Bustos, domiciliado en el Seminario. Archivo FIDAS.

${ }^{25}$ Asi se indica en la crónica que recoge el suceso en las páginas 9 y 10.

${ }^{26}$ En BOAS, núm. extraordinario, 6 de julio de 1952, págs. I-IV.
${ }^{27}$ La valoración la realizan "un prestigioso arquitecto de nuestra ciudad" y “La Unión y el Fénix Español”. En BOAS, XCIII, 1952, pág. 492.

${ }^{28}$ BOAS, núm. extraordinario, 6 de julio de 1952, pág. V.

${ }^{29}$ Aparece nombrado por acuerdo de 8 de julio de 1952, dentro de una comisión presidida por el arzobispo, según se reseña en BOAS, XCIII, 1952, pág. 477.

${ }^{30}$ Es interesante observar la evolución ornamental de estos elementos si tomamos como referencias la fotografia de Lucien Lévy (1883); o la versión ornamentada, todavía presente en imágenes custodiadas en la fototeca del Consejo Superior de Investigaciones Científicas y publicadas justamente por Antonio Sancho Corbacho en 1952, año del incendio (Cfr.: Arquitectura barroca sevillana del siglo XVIII. Madrid: CSIC, 1952, lám. 43); luego, la reconstruida por Illanes y visible en diversas publicaciones difundidas hasta la pasada década de los noventa, hasta llegar a su estado actual.

${ }^{31}$ Cfr. Alberto Villar Movellán: "Arquitectura de José Galnares Sagastizábal". Boletin de Bellas Artes, IX, 1981. También: Eduardo Mosquera Adell y Maria Teresa Pérez Cano: La vanguardia imposible. Quince visiones de arquitectura contemporánea andaluza. Sevilla: Consejeria de Obras Públicas y Transportes, 1990, págs. 198-223.

${ }^{32}$ El proyecto se titula Reforma o Reformas Seminario. Algunos planos localizados van fechados el 6 de agosto de 1962. Fondo Documental del arquitecto José Galnares Sagastizábal, en Archivo Profesional del arquitecto Juan Fernández Carbonell.

${ }^{33}$ El propio Galnares manejó una interesante ortofoto aérea del palacio, previa a su intervención, localizable en su Fondo Documental citado, quizá fechable en los años cincuenta.

${ }^{34}$ Decreto 886/1968, de 6 de abril (BOE núm. 103, de 29 de abril), por el que se declara monut mento histórico artístico el palacio de San Telmo de Sevilla, con el jardín contiguo al mismo.

${ }^{35}$ La transcripción del acta, localizada en la biblioteca de la Real Academia de Bellas Artes de Santa Isabel de Hungría es: 28-Julio-1967. Sres. Congregados: Sebastián Bandarán (Pte, Acctal) / Grosso Sánchez / Sánchez Fernández / Gómez Castillo / Delgado Roig / Collantes de Terán / Galnárez Sagastizabal / Sancho Corbacho / Heliodoro Pino Sardá. “....Llegó a su conocimiento la existencia de una oferta en firme de compra del Palacio de San Telmo, para su conversión en un Hotel, y dad la calidad del edificio, cree conveniente solicitar la expresa declaración de Monumento Nacional del mismo, solicitud que debía hacerse conjuntamente por las corporaciones mas interesadas en su conservación y al mismo tiempo solicitar del Ayuntamiento, Diputación y Comisaria de Defensa del Patrimonio Artistico que se sumen a dicha petición. Los reunidos acordarán por unanimidad todo lo que antecede y dirigir rapidamente la petición a la Dirección General de Bellas Artes...".

${ }^{36}$ La transcripción del acta es la siguiente: 18-Septiembre-1967. Sres. Congregados: Hernández Díaz / Sebastián y Bandarán / Sancho Corbacho / Lerdo de Tejada / Collantes de Terán / Grosso Sánchez / Gomez Millán / Gómez Castillo / Sánchez Fernández / Galnarez Sagastizabal / Castillo Navarro Aguilera / Sánchez Pedrote / Bacarisas Pedestacar / De la Banda y Vargas (Secretario General). ". Votos a favor de Declarar Monumento Nacional el palacio de San Telmo, su mandose el Sr. Alcalde de Sevilla, petición que dirige a la Dirección General de Bellas Artes el Excm. Sr. Presidente de la Diputación Provincial, adhiriéndose a la iniciativa de esta Real Academia de solicitar la Declaración de Monumento...".

${ }^{37}$ Uno tiene visado colegial 100419 y el otro 100642, el último y más reducido. Pero existen documentos previos (memoria, plano, pliego y un primer presupuesto con menor PEM) visados con el número 99986.

${ }^{38}$ En Archivo FIDAS, Expediente 099986. En AGA, Sección Cultura, caja 147

${ }^{39}$ Según reza en la hoja $n^{0} 2$ de la memoria del proyecto.

${ }^{40}$ En AGA, Sección Cultura, caja 62

${ }^{41}$ Archivo FIDAS. Expediente 137824

${ }^{42}$ Tanto para el plano como los informes y memorias: Archivo FIDAS. Legado Antonio Delgado RoigAlberto Balbontín. Pendiente de catalogación.

${ }^{43}$ AGAS, Archivo Personal del Cardenal Bueno Monreal, legajo 19.

${ }^{44}$ A titulo de referencia, pueden recordarse: Guillermo Vázquez Consuegra: "San Telmo". Aparejadores, 11, septiembre, 1983, págs. 17-23. José Maria Vázquez Soto; Guillermo Vázquez Consuegra; Javier Torres Vela: San Telmo. Biografía de un Palacio. Sevilla: Consejería de Cultura, 1990. Teodoro Falcón Márquez: El Palacio de San Telmo. Sevilla: Gever, 1991. 